\title{
O "POPULAR" EM \\ EGBERTO GISMONTI
}

RÚRION SOARES MELO

\section{RESUMO}

Nossa música, rica e moderna, não pode ser integralmente enquadrada em tipologias. Este artigo destaca a importância do material musical e da autonomia nos procedimentos composicionais, e propõe que a compreensão das obras de Egberto Gismonti não pode se restringir aos elementos propriamente "brasileiros" do "nacional-popular".

\footnotetext{
PALAVRAS-CHAVE: Egberto Gismonti; música popular brasileira; nacional-popular.
}

\section{SUMMARY}

Brazilian music, rich and modern, cannot be integrally fit in typologies. This article detaches the importance of the musical material and the autonomy in the compositional procedures, and considers that the understanding of the work of Egberto Gismonti cannot be restricted to strictly "Brazilian" elements of the "nacional-popular".

KEYWORDS: Brazilian music; popular music; Egberto Gismonti; compositional resource.

Mário de Andrade dedicou parte significativa de sua obra aos trabalhos que tinham como objeto a gênese da "música brasileira". Aquestão era complexa e abrangente, pois envolvia o processo de "modernização" e de formação do país, o período de "nacionalização", esteticamente marcado por simplificados dualismos: "arte brasileira" ou "arte internacional", "música popular" ou "música artística" etc. Negando a solução "ou... ou", Mário de Andrade percebera que o valor nacional das obras de nossos artistas era configurado de tal forma que os "dualismos" teriam de ser repensados - ainda que não fossem superados. Tratava-se da recusa das explicações de caráter étnico cuja conseqüência éo "primitivismo", o "exotismo divertido", o "esquisito apimentado"; por outro lado, era a recusa do "universalismo", 
da "arte desinteressada" que não tinha cabimento na fase de construção em que nos encontrávamos. "Todo artista brasileiro", dizia ele, "que no momento atual fizer arte brasileira é um ser eficiente com valor humano. O que fizer arte internacional ou estrangeira, se não for

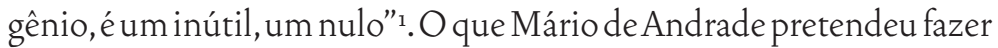
no seu Ensaio sobre a música brasileira foi "repensar" os dualismos por meio de um processo de estilização capaz de fundir, de um modo eficaz, a assimilação de códigos populares a códigos eruditos — sem deixar, é claro, de discutir suas dificuldades.

Mas como o nacionalismo musical ia se deparar com o problema da "adequação, interna à obra, de um código ao outro" ${ }^{2}$, pois haveria impotência no processo de estilização e certa incapacidade do código erudito integrar a cultura do povo, para melhor compreensão da música popular seria preciso introduzir-se no que há de específico no valor nacional de nossas obras. A música genuinamente brasileira é composta de elementos que refletem as características daquilo que muitas vezes foi identificado por "nossa raça", sobretudo aqueles presentes na música popular. O que significa hoje esse engajamento para "nacionalizar nossa manifestação" artística? O compositor brasileiro não deveria se considerar obrigado a fazer uso de determinados ritmos, melodias e harmonias que, em uma acepção porvezes problemática, são como elementos canônicos da música popular. Nossa música, rica e moderna, não pode ser integralmente reconstruída com as tipologias "Esse ritmo é brasileiro", "Essa melodia não é brasileira" etc., nem mesmo se queremos ressaltar a "música popular brasileira" como algo que se configura com elementos característicos da variada manifestação musical tipicamente nacional, levando a um caminho diferente daquele apresentado por Mário de Andrade como solução para tais dualismos. Tudo bem, nem "primitivismo" nem "mera erudição". Mas o material musical "popular" (ritmo, melodia, polifonia, instrumentação e forma) é por demais "determinante" para dar conta de uma gama considerável de obras indubitavelmente brasileiras. Brasileiras, porém populares não mais no sentido de um nacional-popular genuíno. E não são "eruditas" também, se limitamos seu sentido ao conjunto de obras conhecidas como "música clássica". A questão não é reduzida à mera obviedade: rótulos são simplificadores. Ela se configura antes na autonomia da obra, nos procedimentos de composição, no trabalho com o material musical.

Negar a "cor local" em nome da "erudição" poderia significar ser insensível, na construção da obra, diante da imposição real de um conteúdo histórico determinado - o nosso, o popular. "Poderia", tivesse o exclusivismo localista sido ignorante do "fato nacional" 3 , o qual entendemos aqui como um processo de mistura, diversificação e, por conseguinte, enriquecimento do material musical. O contrário é ainda
[1] Andrade, Mário de.Ensaio sobre a música brasileira. São Paulo: Martins, 1972 , p. 19.

[2] Cf. Wisnik, José Miguel. O coro dos contrários: a música em torno da semana de 22. São Paulo: Duas Cidades, 1983 , p. 27.
[3] Andrade, op.cit., p. 27. 
[4] Agradeço a Marcos Nobre por chamar a atenção para ambos os argumentos. mais difícil, pois o Brasil não se aburguesou nos moldes europeus. Assim, esse "conteúdo histórico determinado" já se encontra misturado...e se mantém.

Certamente que para compreendermos ainda melhor o que resultou dessa "história da recepção" que caracteriza o ponto central desse "fato nacional" é preciso uma análise mais aproximada das obras. Diversos compositores seriam representativos desses processos de expansão do material, de Tom Jobim a Hermeto Pascoal. Nossa escolha em favor das obras de Egberto Gismonti pode ser justificada no modo como sua música deixa ver mais facilmente a tensão dos elementos "populares" como recurso composicional, ou seja, como não há vitória do popular (no sentido forte do termo) nem da música "desinteressada", permitindo-nos tirar duas importantes conseqüências 4 : primeira, sua música representa uma resposta diferente à solução que Mário de Andrade deu ao dualismo, uma vez que as obras não podem mais ser compreendidas lançando-se mão dos elementos propriamente "brasileiros" do finado "nacional-popular"; segunda, de acordo com a recepção, houve uma tendência à expansão do material musical, enriquecendo-se os recursos criativos e dinâmicos para a composição. A análise que pretendemos fazer aqui não abrange a gigantesca discografia, nem mesmo toca em aspectos da formação musical de Egberto, mas apenas se debruça sobre alguns elementos e estruturas formais de um número limitado de músicas e discos, não somente por motivo de espaço ao qual o presente ensaio deve se limitar, mas por serem suficientes para apoiar nossas reflexões iniciais a respeito da peculiaridade do "popular" como recurso composicional.

Egberto é um artista brasileiro cujos rótulos dizem muito pouco sobre sua música. É difícil negar seus traços "populares", ainda que bem mais complexos que as manifestações folclóricas ou da música popular de massa que tomou a forma das canções. O estatuto do "popular" em sua obra é sempre refletido e mediatizado nos procedimentos composicionais. O regional nunca vai sem uma pitada de novidade ou sem um sentimento de traição com o passado e com a herança cultural. Ainda assim, a apologia à riqueza dos sons brasileiros lhe dá o norte. E nisso Mário de Andrade tinha razão: a autotematização do imaginário nacional tem um gosto especial, e sobre esse aspecto a música popular é privilegiada. Incorporar isso nas composições não significa panfletar produto interno. Egberto sabe que a linguagem musical do Brasilé tão multifacetada quanto rica. Privilegiar a música pantaneira ou maracatu, misturar instrumentos, melodias e temas de regiões diferentes significa alargar as possibilidades sonoras 
e de composição, ao contrário de um relativismo amalucado como querem alguns. Não se trata nem de nacionalismo desmedido, nem de pós-modernismo periférico. Uma embolada nordestina deve soar de acordo com suas variantes rítmicas e melódicas, respeitar as sobreposições sincopadas, além da assinatura que possui como tipicamente brasileira. Mas não há um traço único que pudesse caracterizar o estatuto do popular. Egberto não se cansa de repetir em entrevistas que "tocar" o Brasil é expor suas "contradições", das desigualdades sociais assim como culturais. E não podemos nos enganar, pois tomar as "contradições" como "fonte" significa expandir o material musical e informá-las (ou seja, dar-lhes forma) no interior dos procedimentos composicionais.Ao mesmo tempo em que há semelhança com relação a Béla Bartók, para quem a música folclórica era não somente um rico material, mas, sobretudo, uma "matriz" técnica, Egberto vê nesse imenso e rico material que constitui a música popular brasileira uma matriz sem unidade para a qual a técnica deverá se ajustar.

Não teríamos problema em dizer que Egberto faz da exceção uma regra. Isso é corrente na negação muito peculiar dos elementos populares. Mas o que encontraremos exemplificadas em suas músicas (e os exemplos certamente poderiam abranger muitas composições) indica que a negação dos elementos populares não quer dizer simplesmente optar pelos procedimentos europeus. Contudo, por que Egberto deveria carregar o fardo do exclusivismo nacional? Não seria antes riqueza musical genuína, do autor e do material? Para os eruditos, no melhor dos casos, ingenuidade historicamente determinada. Historicamente determinado, aceitamos, ainda que com reservas; conformismo diante do material popular, dificilmente. O estatuto do "popular" surge aqui como tensão não resolvida: nem negação total da cultura musical herdada, nem solução na identificação determinada da tradição. Cabe agora investigar mais de perto.

Em seu disco Sanfona, que procurava ser um retrato popular, a miscelânea de estilos regionais é composta com sutileza e os traços mais característicos aparecem muitas vezes de forma implícita. Em "Maracatu”, Egberto mantém uma célula contínua na introdução executada com piano que, ainda sem a percussão, insinua acordes no ritmo do maracatu. Esta "insinuação" passa ao primeiro plano e vira mote para a introdução dos outros instrumentos. A percussão surge apenas no tema, evitando que a bateria se sobrepusesse e entregasse grosseiramente a célula do maracatu. A entrada e a saída dos instrumentos são acompanhadas de uma forte dinâmica, chegando a uma ponte em que permanece somente o piano executando sua repetida célula de duas notas. "Loro", por exemplo, é ainda mais complexa. Trata-se de um baião com a caixa dobrada do frevo, porém o segundo tempo forte é o do maracatu. A melodia tem uma semicolcheia quase constante que 
[5] Cf.Andrade, op.cit., p. 49.

[6] Cf. Tinhorão, José Ramos. História social da música popular brasileira. São Paulo: Editora 34, 1998. amarra, por assim dizer, o ritmo e a harmonia. Todos os elementos estão presentes quase que sub-repticiamente, insinuados, implícitos, quase negados, mas, poressa razão, com uma particularidade original.

Ainda que a harmonia transcenda as nacionalidades (e aqui novamente Mário5), é possível identificar processos diferentes de harmonização quando comparados, no caso, às harmonias populares já existentes. Existem formas harmônicas — que podem ser identificadas com determinadas manifestações folclóricas, regionalmente diferentes, ou estilos com variações próprias - que servem como material comum a partir do qual as diferenciações evariações são estabelecidas. Se voltarmos a "Loro", podemos notar que sua harmonia é, digamos, tradicional, grande parte com cadências em quintas; todavia, as alterações dos acordes, ainda que sujeitas ao temperamento, são mais do que tonalismo harmônico herdado de Portugal - isso porque nossa harmonia popular mais comum é devedora do além-mar ${ }^{6}$. Egberto resolve de forma simples uma cadência "tônica, subdominante e dominante" da seguinte maneira: $\left\{\mathrm{Ab} / \mathrm{Gb}|\%| \mathrm{Db} / \mathrm{F}|\%| \mathrm{E}^{\circ}|\%|\right.$ $\mathrm{Ab} / \mathrm{Eb} \mid \%$. Note-se a inversão dos baixos: sétima, em seguida terça maior, tônica e conclui numa tônica (Ab) com a quinta no baixo (Eb), mas poderia ser um Eb com sexta e décima primeira, tal como indicado por ele na partitura. As inversões não são novidade. Egberto, insistimos, vai além, pois suas incursões no universo harmônico adotam a forma simplificada de inversões e poliacordes de cadências harmônicas consideradas tradicionais, passam por intenções "modais", bastante utilizadas por ele, e chegam aos usos, não raros, de séries inteiras de acordes isolados. "Forrobodó" também é um bom exemplo de saídas simples, mas não convencionais.

Veja-se o caso de "Lundu \# 2". Apesar do centro claramente modal de sua parte inicial (uma intenção menor em $\mathrm{G}$ ), o desenvolvimento harmônico possui aparentemente a lógica dos acordes isolados. Egberto une as dissonâncias harmônicas ao caminho melódico polifônico. "Lundu \# 2" é centralizada no violão, acompanhado por um cello e um baixo. Trata-se de uma espécie de estudo para violão, cujo mote está no tempo forte dos arpejos. Mas como a maior parte do desenvolvimento temático ocorre como se não houvesse separação entre harmonia e melodia, destrói-se a lógica tradicional da análise harmônico-melódica. Os contrapontos e o colorido das vozes constroem a harmonia em sobreposição, com riqueza de graus dos acordes na própria disposição dos arpejos. Aos acordes, qualitativamente diferentes, e dispostos de forma construtiva, vêm somar-se pontes dinâmicas e de descanso. A tensão, no caso, está em fazer descansar o processo construtivo passando pelas consonâncias. $O$ popular aqui se dissolve quase em absoluto. Mas tal é o preço do experimentalismo, impulso dessa tensão cuja vontadeé dissolver e equilibrar.A esponta- 
neidade rompe os elementos tradicionais, faz surgir oposições que no caso se interpenetram, mesmo que o resultado da obra não vá além de uma certa prudência com o novo. Egberto não radicaliza o universo formal, se com isso entendemos que Schönberg fora um ícone da nova música. Longe disso. Mas a atualização do popular no primeiro é semelhante, quanto à gênese, da atualização da tradição nas obras experimentais do segundo7. O "fato nacional" insere-se voluntariamente na construção formal da harmonia, seja ao olhar para trás, ao recuar diante de possibilidades mais progressivas quanto ao trato com o material, seja nas incursões, expansivas quanto ao seu resultado, de um refinamento quase que desinteressado.

Mais um caso exemplar. A obra (erudita?) "Natura, festa do interior", com mais de 33 minutos divididos em quinze partes, é como se fossem capítulos de uma história em que os protagonistas vão se envolvendo em tramas cada vez mais complexas, as personagens aos poucos se contradizendo e se diluindo na vaga "progressista" que impele todas as passagens a se submeterem ao sentido total de um drama não reconciliador. Brasileira, certamente. E exatamente por isso, expõe nossas "contradições". O recurso usado por Egberto reside na justaposição entre "expressão" e "construção"8. O que Wisnik comentou sobre Mário de Andrade, em relação à divisão profundamente conflitiva entre esses dois tipos de abordagem, vale para Egberto: “[...] a leitura consciente, técnica, que deixa ver claramente a estrutura formal chamando a atenção sobre a linguagem, e a leitura envolvida, que apela para o inconsciente, que subjuga a razão e ameaça despertar a magia" 9 .

Ainda em "Natura, festa do interior", a cor local, insinuada com delicadeza pela introdução do piano, é claramente nordestina, da síncopa do baião; delicada, sua primeira parte aceita no máximo a intromissão do cello e seu caminho harmônico é por vezes suspenso efeito de uma certa impaciência, impelido por algo a que se quer chegar e que força, na medida do possível, abrir novos rumos. A intenção modal frígio maior, último passo da parte 1, surge como um "Chega!...". E é precisamente o que acontece. Uma brusca ruptura, começa a parte 2, e o experimentalismo jorra seus elementos espontâneos, descompassados, aleatórios. Aqui não há mais polifonia, mas apenas "sustos", timbres antes dos ruídos que dos sons, reflexos incontroláveis, como se adentrássemos nas pulsões inconscientes, não racionáveis, da expressão pura e simples. Porém, a contrapelo da expressão, a construção está presente: os "sustos" são uníssonos, perfeição matemática construída pelo piano e pelo cello. As harmonias, que são, por momentos, base apenas para a síncopa - que, acreditem, mantém-se como em um grande baile popular -, em outros momentos são apenas pano de fundo para a tensão melódica, esta sim atonal
[7] Cf. Adorno, Theodor W. "Arnold Schoenberg (1874-1951)", Gesammelte Schriften 10.1. Frankfurt/M: Suhrkamp, 1997.

[8] Idem, Ästhetische Theorie. Gesammelte Schriften 7. Frankfurt/M: Suhrkamp, 1997, pp. 72-4.

[9] Wisnik, op.cit., p.114. 
[10]Schönberg, Arnold. Harmonia. São Paulo: UNESP, 2001, p. 197. e dispersa na dinâmica das expressões. Tensão seguida pelas tranqüilas terceira e quarta partes (e aqui avançamos os onze minutos). Tal tranqüilidadeé perturbada por raras dissonâncias que se insinuam no piano, entre quase mentirosas soluções bem temperadas. Estas soluções se sustentam com muita dificuldade - a tríade maior é acompanhada ora por intromissões da nona maior ou da quinta aumentada, ora pelas atrevidas modulações de meio-tom.

Certamente demoramos muito tempo para nos apropriar dos recursos harmônicos já sugeridos por Schönberg em seu tratado de harmonia, orientando-nos a fazer uso de "uma harmonia flutuante, de uma harmonia, por assim dizer, infinita, que não precisa trazer consigo atestado de procedência e passaporte para explicar minuciosamente de onde veio e para onde se dirige"10. Muitos brasileiros, e claro, Egberto, seguiram tal orientação não somente como simples tentativa e erro. Isso se decifra formalmente em detalhes voluntários aparentemente simples, como na desconfiança com as vozes dos acordes, evitando-se a utilização de cadências "quadradas" - aquele impulso à subdominante em que se evita que se desvaneça a tônica (por exemplo, um C) em uma quinta (do F) se àquela é acrescentada a quarta (o F) em uma oitava abaixo etc. - ou nas conclusões ultrapassadas (por exemplo, o V, I; IVm, I; ou mesmo IV, V, I). Nota-se que a cor local é traduzida em elementos específicos da construção conceitual tornandose muito mais reflexiva que as soluções mais simples que inevitavelmente caracterizam e determinam a música popular. Esta pode ser alterada sem que a composição de característica "brasileira" perca sua unidade formal. Muitos são os ganhos, dizia Schönberg, quando optamos por trabalhar os elementos tradicionais, por exemplo, a tonalidade, de uma forma apenas "sugerida", "pouco nítida". Quando a sugestão tonal é racionalizada como procedimento, a consonância torna-se um elemento de construção do todo e os acordes isolados tornam-se negações determinadas.

Avariedade do material musical e dos procedimentos composicionais deixa-se ver então em diferentes momentos da configuração e da estruturação da obra. A referência explícita a estilos musicais característicos é uma constante na maior parte de seus discos, bem como o entrecruzamento de células, mistura de ritmos e o alargamento harmônico-melódico, como vimos acima. Acrescentamos a isso a instrumentação muitas vezes pouco convencional, mas sempre determinante de traços e cores musicais bem específicos. O material e a forma, por fim, ainda são apresentados com abordagens mais expressivas ou com estruturas rígidas de construção. A organização de uma obra como Soldo meio dia, para ficar apenas com um exemplo, resulta desses diversos elementos colocados em ação simultaneamente, e isso não apenas em relação à diversidade de linguagens na comparação de uma 
música com a outra (a embolada e o berimbau de "Kalimba (Lua cheia)" e a dinâmica bem leve do piano de "Coração (Saudade)"), mas na utilização da variedade do material presente no interior de cada composição (como em "Raga (Festa da construção)").

III

Oespecialista, fazendo incursões ora construtivistas, ora expressionistas, é misturado com a característica, um tanto paradoxal, do contemplador da natureza e de suas leis que podem ser traduzidas para a música. Há o tema da reconciliação com a natureza, que sofre não somente pelos termos que quer reconciliar, mas pelo meio com que quer expressá-la - e isso é fundamental na compreensão da utilização do material. A relação entre "arte" e "natureza", tão íntima em Egberto, é mais um modo de diferenciar-se de Mário de Andrade, para quem "a arte não consegue reproduzir a natureza, nem este é seu fim" ${ }^{11}$. Para Mário de Andrade a música é definida como uma arte não mimética. "Natura, festa do interior" é uma música dedicada ao Pantanal. Para exprimir uma condição "não mentirosa" em que Egberto incorpora a natureza no conteúdo e na forma da composição, é preciso ressaltar não a contradição, mas a dialética, muito particular, de sua solução. Solução esta que, apesar da semelhança das citações, é mais shönbergiana que marioandradiana. "As tentativas", novamente Schönberg, "de conduzir o artista ao terreno do natural fracassarão por muito tempo ainda. [...] as leis naturais não conhecem exceções; as teorias da arte compõem-se, antes de tudo, de exceções"12. Procurando ser o mais fiel possível ao espírito e à letra desta citação, diríamos que o Pantanal não pode representar, no caso do material musical, o sistema tonal íntegro, perfeito e acabado. Egberto avança para além das fronteiras desse sistema quase corriqueiramente. Sua solução consiste antes em representar a natureza com meios autônomos, no desdobramento de leis próprias à música, inviabilizando o determinismo das leis da natureza então contempladas, isto é, tornando os detalhes que figuram como ordenação "bem temperada" da natureza quase que incomensuráveis e intransparentes para o material e a forma que utiliza.

É difícil representar a regra com a exceção - sempre há uma pequena passagem cuja construção é por demais racional, por demais dominadora dessa natureza; ou sempre há o momento em que o compositor decide arbitrariamente mudar o curso das águas do rio. Talvez sua falha tenha sido, por vezes, "reconciliar" (se é que o termo cabe neste caso) de forma exterior e quase artificial, como nas suas digressões que apelam para uma espécie de "mantra" nos longos arpejos dóricos ou lídios, os recursos à intenção modal que soam repetitivos e cansativos: poderíamos arriscar que, nestes casos, veríamos seus
[11] Mário de Andrade citado em Wisnik, op.cit., p. 90.

[12] Schönberg, op. cit., p. 46. 
[13] Barros, Manoel de. "Vespral de chuva".In:Gramática expositiva do chão (poesia quase toda). Rio de Janeiro: Civilização Brasileira, pp. 234-5.

[14] Adorno, "Philosophie der neuen Musik". Gesammelte Schriften 12. Frankfurt/M: Suhrkamp, 1997, p. 55 . momentos mais "místicos" e menos interessantes. Suas "boas" soluções freqüentemente são tensas - em vez do "mantra" e de sua identificação espiritual com o mundo natural, Egberto assume na maior parte das vezes a "não-identidade" dos elementos reais da natureza na forma "particular" dos elementos musicais: seja nos pequenos detalhes e alterações nos ritmos, na instrumentação, seja na fusão do baião executado com uma complexa matemática de arpejos, seja nas canções "tradicionais" que aceitam acordes alterados etc.

No Pantanal, a vida natural não se configura de forma homogênea, como "uma" natureza, mas como constante transformação e luta de vida e de morte. Nesse sentido, assim como indica o título do disco, trata-se de uma "música de sobrevivência". Por esse motivo, também, Egberto pede, no disco, que se leia a poesia de Manoel de Barros "Vespral de chuva" antes da audição da música "Natura, festa do interior". A poesia começa descrevendo o marasmo de um dia de muito calor ("Nem folha se move de árvore. Nenhum vento"). Este marasmo esconde uma terrível angústia na espera pelos "prelúdios da chuva" que "está se arrumando no bojo das nuvens". A agitação constantee é sinal de sobrevivência, e a vida, que estava por um fio, prepara-se agora para a vinda das águas. "Caem os primeiros pingos. Perfume de terra molhada invade a fazenda. O jardim está pensando... em florescer"13.

É evidente que estamos atribuindo a Egberto uma concepção (adorniana!) de natureza que é mais exigente do que nosso compositor "popular" poderia suportar. Mas ao menos Egbertoé supersticioso em relação à música "orgânica", e exemplos não nos faltam para articular a construção requerida com que empregava os recursos progressistas de racionalização do material. "Nenhuma convenção", comentara Adorno sobre a radicalidade schönbergiana, "proíbe ao compositor as sonoridades de que tenha necessidade em um determinado momento e, apenas nesse momento, nenhuma convenção o obriga a adaptar-se ao caráter universal antigo"14. Vide a parte 2 de "Natura, festa do interior". As leis do sistema tonal, por exemplo, de mãos dadas com a polifonia popular, são, aos olhos de Egberto, muito pouco naturais, ou melhor, por demais unilaterais e convencionais. Estão sempre presentes na obra do autor, mas, vale acrescentar, são sempre esculpidas com propriedade, porque sua negação atesta contra o estado de "não-liberdade" a que a natureza foi coagida. Ao compor de acordo com as leis autônomas da música, a "boa" solução de Egberto consegue ser também crítica. Ora, caso a liberdade sonora não seja levada em consideração, as leis do sistema tonal que pretendem ser universais só podem ser tratadas agora como "segunda natureza": as leis "universais" da natureza (a primeira) não são a razão de ser do trabalho com o material e do procedimento composicional. E isso não significa que a música não pode tentar representá-la sem colocar em xeque sua pró- 
pria autonomia. Devido ao procedimento reflexivo com que os elementos caracterizados como "populares" em Egberto são reelaborados formal e progressivamente, o resultado é uma homenagem freqüentemente dissonante e complexa feita à natureza.

A imagem da natureza como condição-limite da sobrevivência expressa, portanto, um potencial mimético conflituoso que é informado na composição não segundo procedimentos dogmáticos cristalizados, mas sim como liberação do material para a diversidade e para sua expansão. E nisso consiste o ponto principal dessa nossa reflexão: a expansão do material no seio das determinações locais permite uma reconsideração da criação do "popular" brasileiro sem que fiquemos presos aos termos impostos pelo "dualismo", bem como alivia o recurso criativo e dinâmico da composição dos elementos rigidamente substantivos do "nacional-popular"15.

RÚRION SOARES MELO é mestre e doutorando em Filosofia pela FFLCH-USP e pesquisador do núcleo Direito e Democracia do Cebrap.
[15] Referências de Egberto Gismonti As composições "Raga (Festa da construção)", "Kalimba (Lua cheia)" e "Coração (Saudade)" encontram-se no disco Sol do meio dia, ECM, EMIOdeon, 1978; "Maracatu" e "Loro", no disco Sanfona, ECM, 1981; "Lundu \# 2" e "Natura, festa do interior", no disco Música de sobrevivência, ECM, 1993; " "Forrobodó", no disco Zig Zag, ECM, 1996.

Recebido para publicação em 11 de março de 2007.

\section{NOVOS ESTUDOS}

CEBRAP

78 , julho 2007

pp.191-200 